\title{
SIG Pada Badan Lingkungan Hidup Dan Riset Daerah Provinsi Gorontalo
}

\author{
Budiyanto Ahaliki ${ }^{\text {**) }}$ \\ Ruly Sinukun ${ }^{2 *}$
}

Program Studi Teknik Informatika, Politeknik Gorontalo email : budiyanto_ahaliki@poligon.ac.id email : rulysinukun@poligon.ac.id

\begin{abstract}
Abstrak-Pengelolaan lingkungan hidup di Provinsi Gorontalo harus ada upaya yang dapat merumuskan sesuatu lingkungan hidup dalam hubungan yang teratur dan logis sehingga membentuk suatu sistem yang berarti secara utuh, menyeluruh, dan terpadu yang dilakukan guna melestarikan fungsi lingkungan hidup dan mencegah terjadinya pencemaran dan kerusakan lingkungan hidup. Di lihat dari kondisi lingkungan dan kecenderunganya, seperti lahan, hutan, sungai, dan pesisir pantai. Dalam penyajian informasi lingkungan hidup pada Badan Lingkungan Hidup dan Riset Daerah (BLHRD) Provinsi Gorontalo, masih berbentuk gambar peta berwarna. Untuk itu diperlukan suatu Sistem Informasi Geografis Pada Badan Lingkungan Hidup Provinsi Gorontalo, yang dapat menyajikan informasi secara geografis, dengan memperlihatkan kondisi lingkungan hidup yang mengalami perubahan ukuran, seperti jarak, luas suatu area, yang disebabkan oleh faktor alam, dengan menentukan titik koordinat lokasi lahan, hutan, sungai, pesisir pantai, sehingga informasi yang disajikan lebih efisien melalui visualisasi dalam bentuk data dan informasi yang dikaitkan dengan kondisi geografis suatu wilayah. Dan dapat membantu petugas BLHRD untuk menyajikan informasi dari kawasan lingkungan hidup menjadi lengkap dengan menentukan titik-titik lokasi koordinat yang di perlukan. Sistem dibangun menggunakan google maps untuk mengolah data dalam bentuk grafis pemetaan, dan databases MYSQL. Untuk permodelan menggunakan UML (Unified Modeling Language).
\end{abstract}

Kata kunci - UML (Unified Modeling Language), Sistem Informasi Geografis, google maps, MYSQL

\section{PENDAHULUAN}

Provinsi Gorontalo terletak di Pulau Sulawesi bagian utara atau di bagian barat dari Provinsi Sulawesi Utara memiliki 1 kota dan 5 kabupaten. Provinsi Gorontalo dibentuk berdasarkan Undang-Undang Nomor 38 tahun 2000, dan secara administrative terpisah dari Provinsi Sulawesi Utara sejak tanggal 16 Februari 2001. Berdasarkan Data Sensus Penduduk tahun 2012, Badan Lingkungan Hidup Provinsi Gorontalo, Luas wilayah provinsi gorontalo $12.435,00 \mathrm{~km}^{2}$ dengan jumlah penduduk sebanyak 1.084.192 jiwa. Untuk itu dalam pengelolaan lingkungan hidup di Provinsi Gorontalo harus ada upaya yang meguraikan dan merumuskan sesuatu

\author{
Mohamad Ibrahim ${ }^{3)}$ \\ Program Studi Teknik Informatika, Politeknik Gorontalo \\ 60111, email : mohamadibrahim35@gmail.com
}

lingkungan hidup dalam hubungan yang teratur dan logis sehingga membentuk suatu sistem yang berarti secara utuh,

menyeluruh, dan terpadu yang dilakukan guna melestarikan fungsi lingkungan hidup dan mencegah terjadinya pencemaran dan kerusakan lingkungan hidup dengan cara melakukan perencanaan, pemanfaatan, pengendalian, pemeliharaan, pengawasan, dan penegakan hukum. [1]

Di lihat dari kondisi lingkungan dan kecenderunganya, seperti lahan, hutan, sungai, dan pesisir pantai. Dalam penyajian informasi lingkungan hidup pada Badan Lingkungan Hidup dan Riset Daerah (BLHRD) Provinsi Gorontalo, masih berbentuk gambar peta berwarna. Hal ini merupakan suatu kendala tersendiri yang dihadapi, mengingat jika kondisi suatu lingkungan terjadi perubahan ukuran seperti, jarak luas lahan, hutan, sungai dan pesisir pantai, suatu area lingkungan tidak dapat divisualisasikan secara jelas. [1]

Untuk itu diperlukan suatu Sistem Informasi Geografis Pada Badan Lingkungan Hidup Provinsi Gorontalo, yang dapat menyajikan informasi secara geografis, dengan memperlihatkan kondisi lingkungan hidup yang mengalami perubahan ukuran, seperti jarak, luas suatu area, yang disebabkan oleh faktor alamiah, dengan menentukan titik koordinat lokasi lahan, hutan, sungai, pesisir pantai, sehingga informasi yang disajikan lebih efisien. Melalui visualisasi dalam bentuk data dan informasi yang dikaitkan dengan kondisi geografis suatu wilaya.

Data tersebut dari sistem informasi lingkungan hidup provinsi gorontalo, yang sampai saat ini belum mempunyai suatu sistem pemetaan yang dapat membantu petugas BLHRD untuk menyajikan informasi dari kawasan lingkungan hidup menjadi lengkap dengan menentukan titik-titik lokasi koordinat yang di perlukan.

\section{METODE PENELITIAN}

\subsection{Analisa Sistem}

Analisa sistem merupakan penguraian dari suatu sistem yang utuh kedalam bagian-bagian komponennya dengan maksud untuk mengidentifikasi dan mengevaluasi permasalahan, pada bagian ini penulis mencoba menganalisa sistem yang sudah berjalan pada Sistem Lingkungan Hidup Provinsi Gorontalo. 
Tabel 2.1 Bagan Alir Analisis Sistem Yang Berjalan

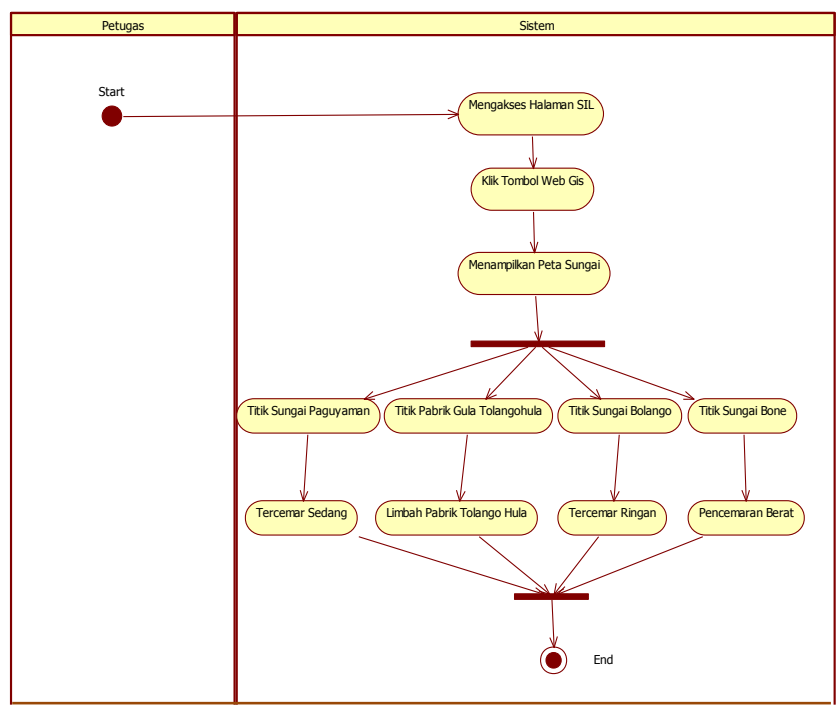

Analisa bertujuan menganalisa sistem yang ada agar dapat dilihat kekurangan dari sistem itu sendiri, hal ini dilakukan untuk memperbaharui sistem yang ada. Adapun sistem yang berjalan pada sistem lingkungan hidup provinsi gorontalo terlihat pada gambar 2.1 diatas.

\subsection{Use Case Diagram Sistem Usulan}

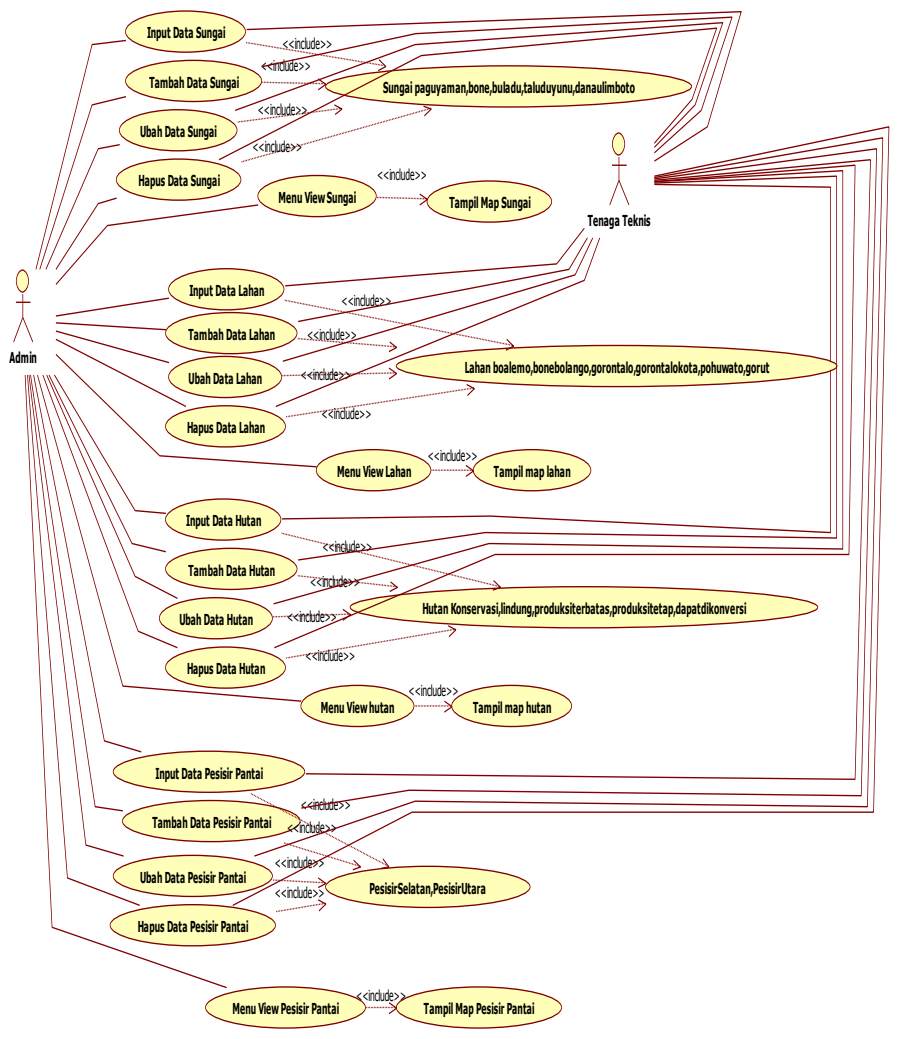

Gambar 2.1. Bagan Alir Sistem Usulan

\subsubsection{Activity Diagram Data Sungai}

Tabel 2.2 Activity Diagram Data Sungai

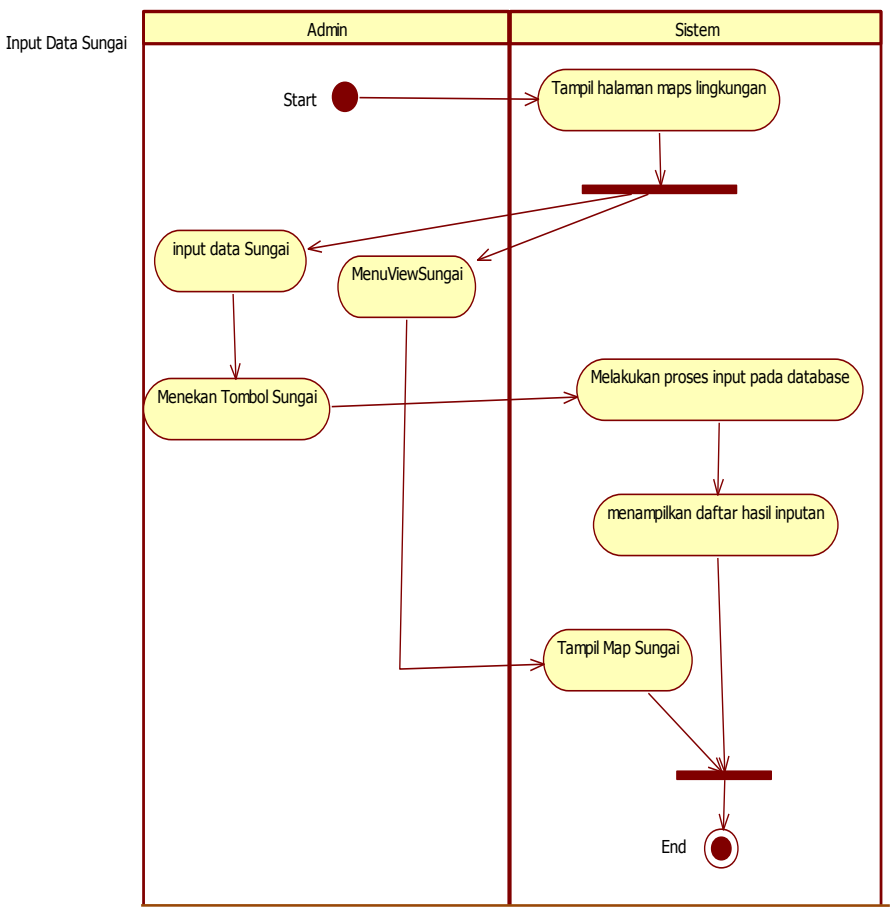

\subsubsection{Activity Diagram Data Lahan}

Tabel 2.3 Activity Diagram Data Lahan

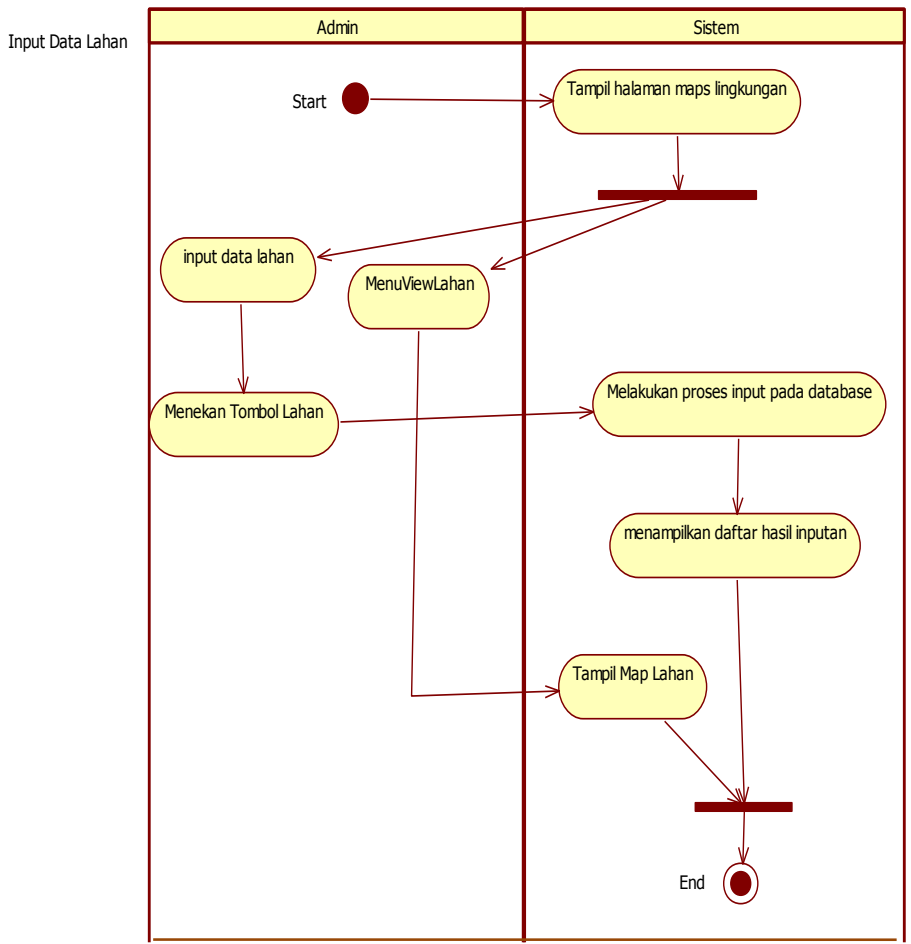




\section{HASIL DAN PEMBAHASAN}

\subsection{Hasil}

\subsubsection{Halaman Masuk Sistem}

Berikut tampilan halaman masuk sistem SIG BLHRD yaitu halaman yang dapat diakses oleh semua user baik administrator atau teknisi dalam melakukan proses masuk kedalam sistem atau disebut (Proses Login).

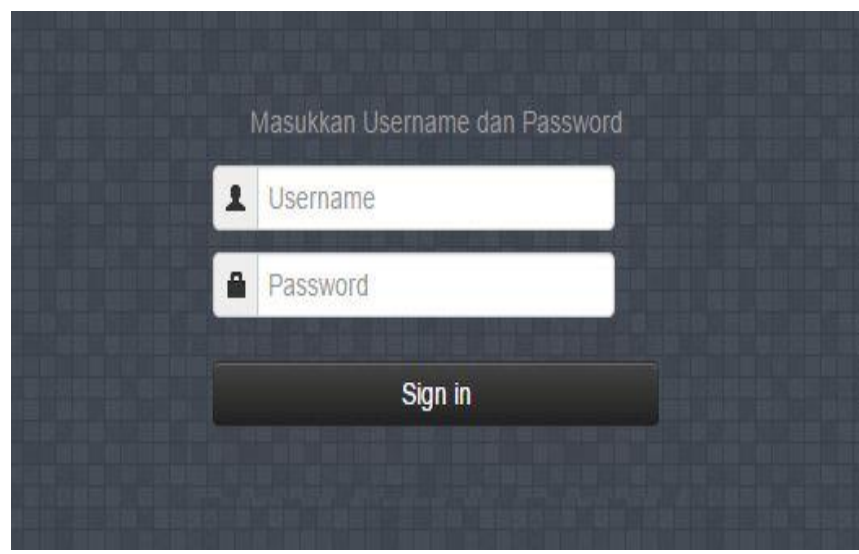

Gambar 3.1 Halaman Masuk Sistem

\subsubsection{Halaman Administrator}

Halaman administrator merupakan tempat untuk melihat dan mengatur sistem geografis (BLHRD). Pada halaman administrator terdapat beberapa menu yaitu dashboard, lihat pemetaan, users, maps, dan data maps.

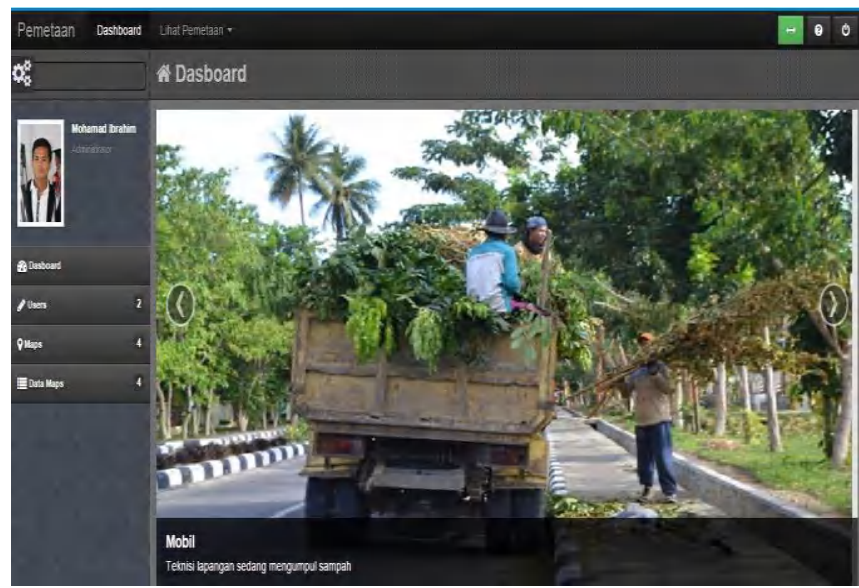

Gambar 3.2 Halaman Administrator

\subsubsection{Lihat Pemetaan}

Мenu lihat pemetaan memiliki beberapa sub menu yang dapat kita lihat yaitu lihat pemetaan hutan, lahan, pesisir pantai, dan sungai. Data-data lihat pemetaan tesebut menginformasikan tentang identitas lingkungan hidup yang ada di provinsi gorontalo berikut contoh menu map hutan.

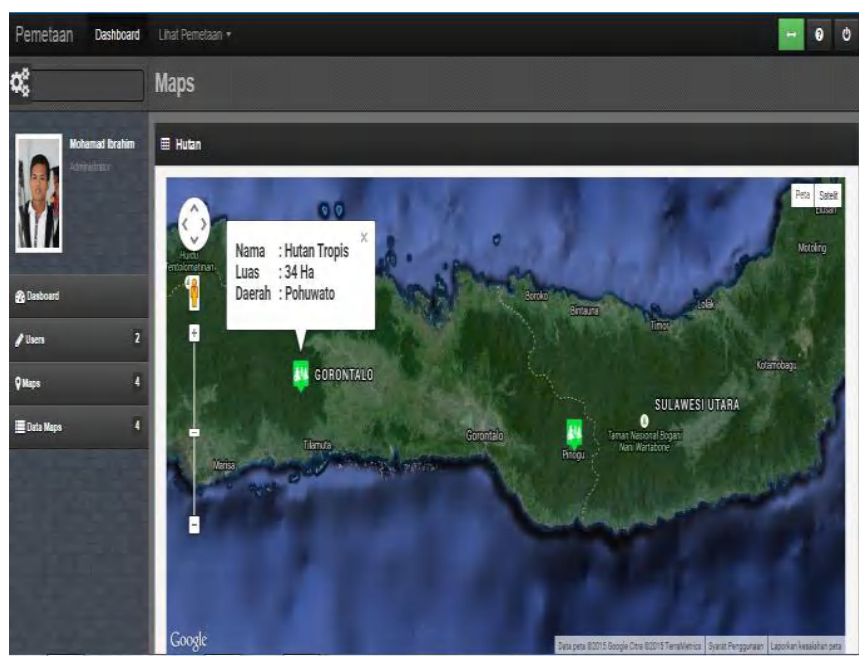

Gambar 3.3 Map Hutan

\subsubsection{User Level Teknisi}

User level teknisi hanya dapat mengakses atau melihat data maps yang telah teknisi tambahkan ataupun administrator tambahkan. Dan dapat menambahkan data maps, Tetapi tidak dapat mengakses menu lihat pemetaan, yang didalamnya terdapat titik-titik sebuah data sungai, lahan, hutan dan pesisir pantai.

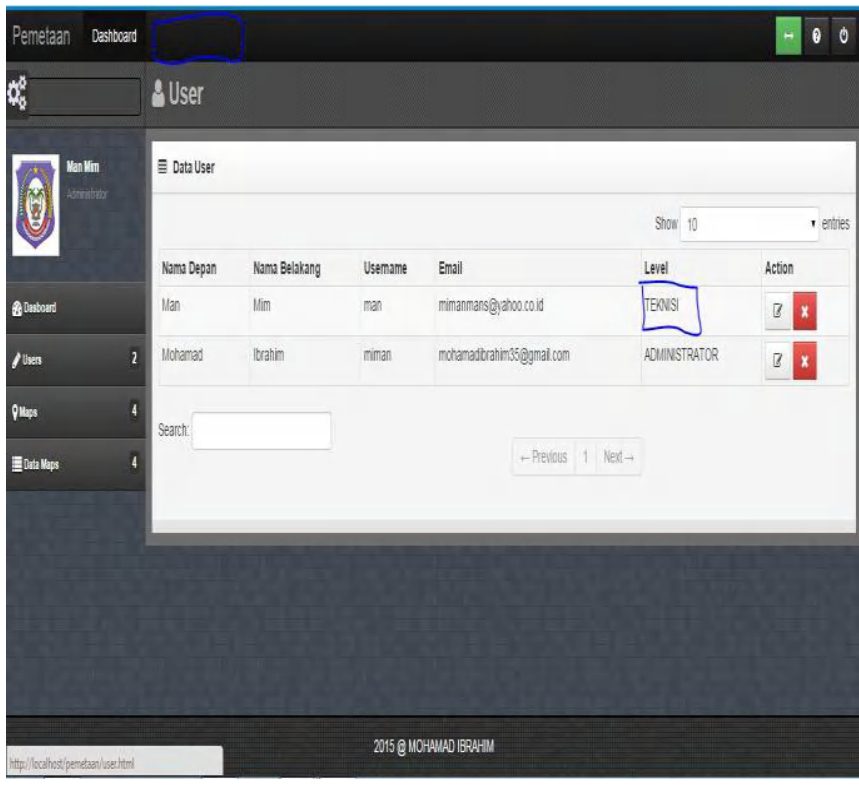

Gambar 3.4 User Level Teknisi

\subsubsection{User Level Administrator}

User level administrator dapat mengakses semua, melihat data maps, menambahkan data maps, edit data maps, hapus data maps, menambahkan user teknisi, edit user teknisi, menambahkan user administrator, edit user administrator, hapus user administrator, dan dapat melihat titik-titik data sungai, lahan, hutan, dan pesisir pantai. Atau dapat mengakses menu lihat pemetaan. 


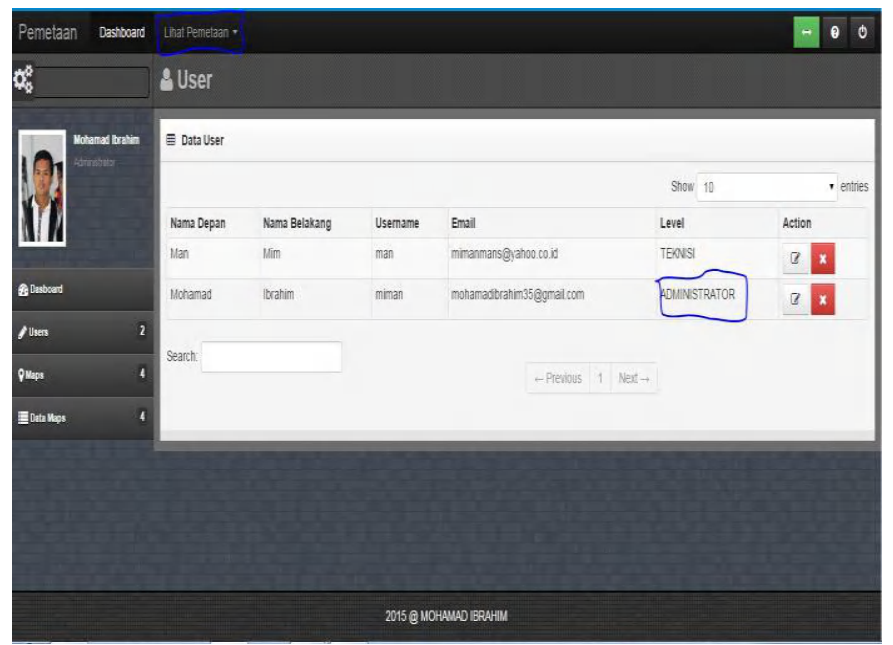

Gambar 3.5 User Level Administrator

\subsubsection{Maps}

Mепи maps merupakan menu yang berisi tambah data sungai, tambah data hutan, tambah data pesisir pantai, dan tambah data lahan. Berikut contoh penjelasan dari data maps sungai.

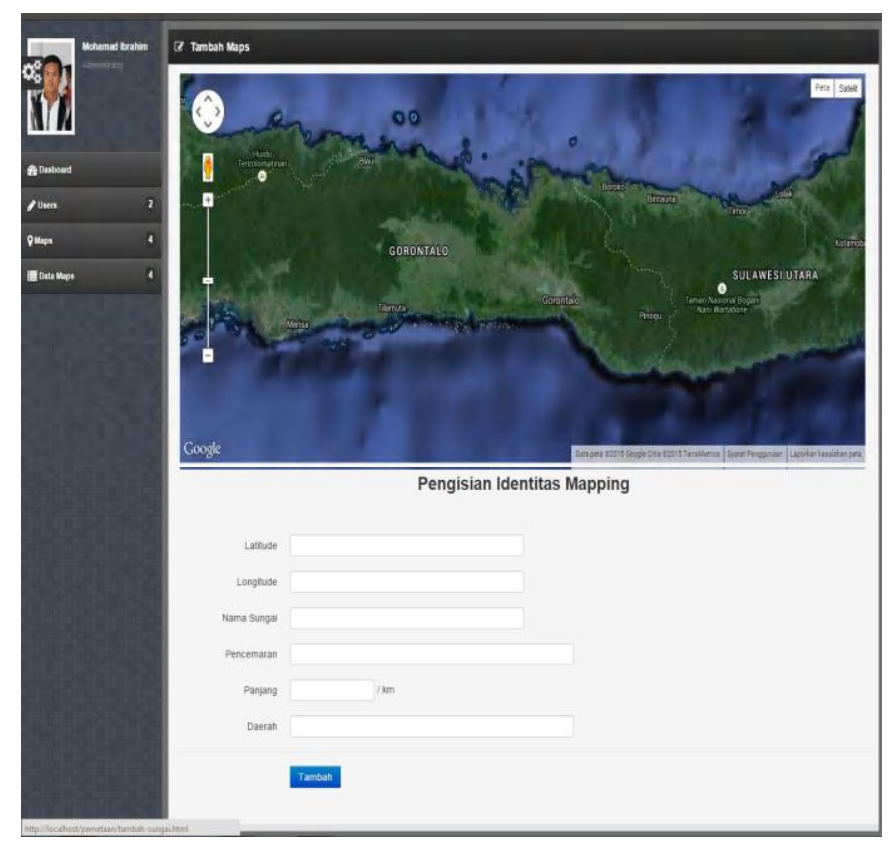

Gambar 4.6 Tambah Data Sungai

\subsubsection{Data Maps}

Menu data maps merupakan menu yang menampilkan data sungai, data hutan, data pesisir pantai dan data lahan. Dimana data-data tersebut dapat kita ubah dan dapat kita hapus. Berikut Deskripsi data maps Sungai.

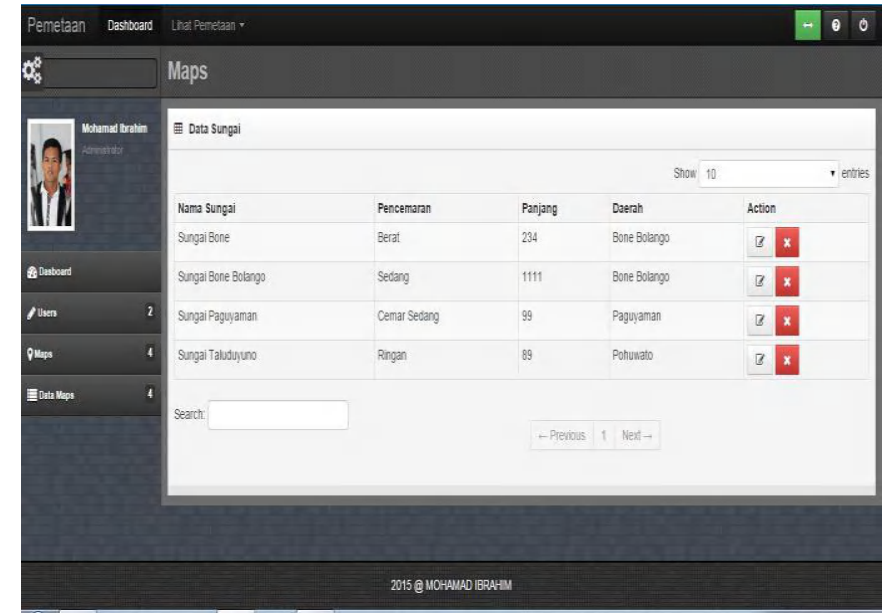

Gambar 3.7 Data Sungai

\subsubsection{Halaman Tentang}

Halaman tentang merupakan tampilan menu yang berisi tentang sistem yang di buat oleh administrator, menginformasikan sistem geografis pemetaan Badan Lingkungan Hidup dan Riset Daerah secara jelas.

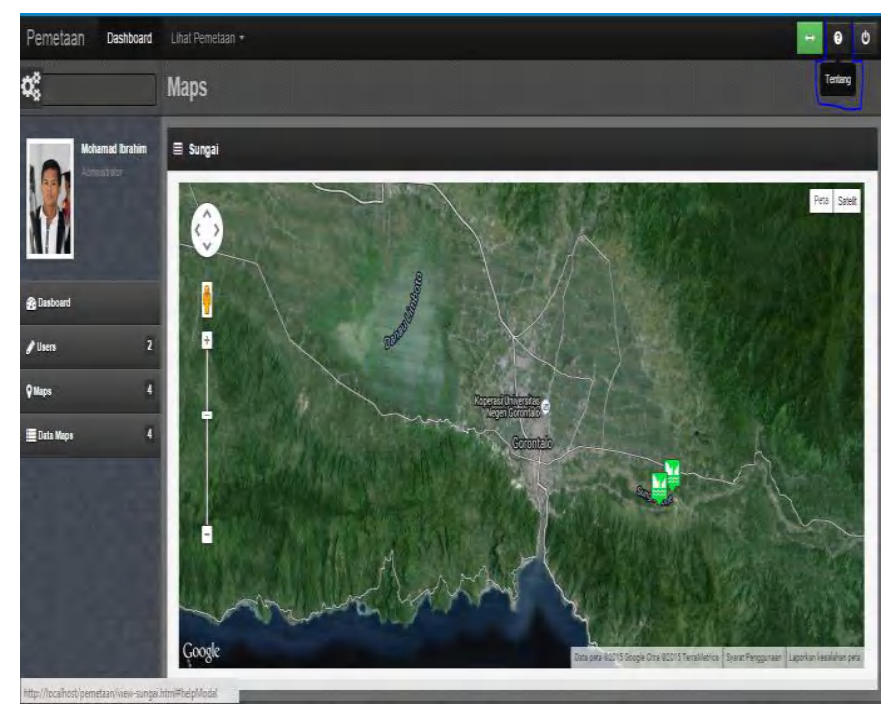

Gambar 4.8 Halaman Tentang

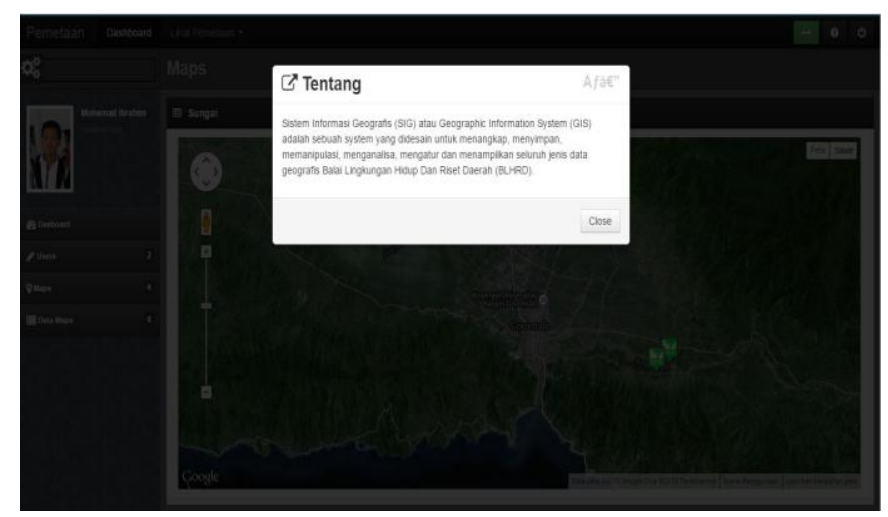

Gambar 4.9 Halaman Tentang 


\section{KESIMPULAN}

\subsection{Kesimpulan}

1. Dapat mempermudah pencarian data lokasi lingkungan seperti lahan, hutan sungai, dan pesisir pantai, berupa titiktitik atau pusat lokasi lingkungan hidup di provinsi gorontalo.

2. Pihak user dapat menambahkan data baru terkait data lahan, hutan, sungai, dan pesisir pantai, yang ada di Provinsi Gorontalo.

\subsection{Saran}

1. Untuk penelitian selanjutnya, penentuan titik koordinat sangatlah penting untuk mendapatkan data yang tepat sehingganya digunakan (GPS) Global Positioning System, yang dihubungkan ke sistem informasi geografis untuk menentukan letak permukaan bumi dengan bantuan penyelarasan, sehingga proses pencarian dan penanggulangan lingkungan hidup bisa lebih baik lagi.

2. Ditambahkan modul untuk membaca data GPS titik koordinat pada sistem setelah titik koordinat didapat dari tempat pengambilan data.

3. Selain menggunakan (GPS) sistem ini bisa di kembangkan dalam bentuk mobile agar penginputan titik lokasi dapat dilakukan dimana saja dengan syarat menggunakan koneksi internet.

\section{DAFTAR PUSTAKA}

[1] Perlindungan Pengelolaan Lingkungan Hidup (ISSN : 2337-4608) Hal 5.

https://books.google.co.id/books?id=6Ib3AgAAQBAJ\&pg =PA3\&dq=lingkungan+hidup+adalah\&hl=id\&sa=X\&ei=8 NmSVM3dCobIuATOgoGYDA\&ved=0CB8Q6AEwATg $\underline{\mathrm{K} \# \mathrm{v}=\text { onepage \&q=lingkungan } \% 20 \text { hidup } \% 20 \text { adalah } \& \mathrm{f}=\text { fals }}$ e diakses tanggal 18 desember 2014.

[2] IRWANSYAH EDY, 2013, "Sistem Informasi Geografis" (Studi Kasus :Sistem Informasi Geografis Badan Lingkungan Hidup Provinsi Gorontalo)", Digibooks, Yogyakarta. Burrough, 1986. Aronoff, 1989. ESRY, 2004. Hal 1.

[3] Sugiarti yuni, 2013, “analisis \& perancangan uml”, graha ilmu, yogyakarta. Hal 34.

[4] Masruri Hilmi Muhammad, 2013, "Membangun Website Super Canggih Dengan Joomla3", PT Elex Media Komputindo, Jakarta. Hal 2.
[5] Komputer Wahana, 2014, "Mudah Membuat Aplikasi SMS Gateway Dengan Codeigniter", PT Elex Media Komputindo, Jakarta. Hal 4.

[6] Ardhana Kusuma YM., S.T., 2014, "Project PHP \& MYSQL Membuat Website Buku Digital", Jasakom.com, Purwokerto. Hal 45. 